\title{
Vigilância sanitária na imprensa brasileira: panorama da cobertura midiática da agência reguladora federal'
}

\section{Health surveillance in the Brazilian press: overview of the media coverage of the federal regulatory agency}

\section{Nayane Yuri Taniguchi Cunha ${ }^{a}$ \\ (iD) https://orcid.org/0000-0002-0087-1960 \\ E-mail: nayanetaniguchiळgmail.com}

Wagner Robson Manso de Vasconcelos

(D) https://orcid.org/0000-0002-2164-1339

E-mail: wagner.vasconcelosळfiocruz.br

\section{Mariella Silva de Oliveira-Costa ${ }^{a}$}

(iD) https://orcid.org/0000-0003-4853-3677

E-mail: mariella.costa®fiocruz.br

${ }^{a}$ Fundação Oswaldo Cruz. Gerência Regional de Brasília. Brasília, DF, Brasil.

\section{Correspondência}

Mariella Silva de Oliveira-Costa

Fiocruz Brasília - Assessoria de Comunicação

Avenida L3 Norte, s/n, Campus Universitário Darcy Ribeiro, Gleba A. Brasília, DF, Brasil. CEP: 70.904-130.

\section{Resumo}

O artigo apresenta um panorama da Agência Nacional de Vigilância Sanitária (Anvisa) na imprensa brasileira. A amostra é composta por textos publicados em 2018 em diferentes veículos impressos e on-line, totalizando 1.629 publicações de 148 veículos de comunicação distintos. A partir da análise de conteúdo, observou-se que a Anvisa não é a principal fonte na maior parte dos textos sobre vigilância sanitária na imprensa, bem como não é apresentada como órgão do Sistema Único de Saúde (SUS), e que os principais temas pautados no período foram relacionados à regulamentação, aos registros e às autorizações. Dentre os assuntos sob sua responsabilidade, o mais frequente foi relacionado à área de medicamentos e farmacopeia. 0 mês de julho registrou uma frequência maior de textos devido à repercussão nacional do caso da morte da paciente de um cirurgião plástico e influenciador digital pelo uso de um produto autorizado pela agência. É importante que a Anvisa reveja o seu posicionamento junto à imprensa, ampliando nos meios de comunicação o seu espaço de fala como protagonista da vigilância sanitária brasileira. Os resultados da análise sugerem tendências da cobertura nacional e podem ajudar a melhorar as estratégias de comunicação não só da Anvisa, mas também de outros órgãos de saúde .

Palavras-chave: Saúde na Comunicação de Massa; Jornalismo; Vigilância Sanitária; Imprensa; Comunicação em Saúde. 


\section{Introdução}

The article presents an overview of the Brazilian media coverage of the Brazilian Health Regulatory Agency (ANVISA). The sample consists of texts published in different print and online media throughout 2018, totaling 1,629 publications from 148 different media. Data underwent content analysis, showing that most texts on health surveillance in the press do not approach ANVISA as the main source nor as a body of the Brazilian Unified Health System (SUS). The main themes in the period were related to regulation, records, and authorizations. Among the subjects under the Surveillance Agency responsibility, the most frequent were related to medication and pharmacopoeia. Given the national repercussion involving the death of a patient of a digital influencer and plastic surgeon, due to the use of a product authorized by the agency, most publications date from July. ANVISA must review its position with the press, expanding its role as a protagonist of Brazilian Health Surveillance in the media. The results suggest trends in national coverage and may help improving the communication strategies not only of ANVISA, but also of other health agencies.

Keywords: Health in Mass Communication; Journalism; Health Surveillance; Press; Health Communication.
As questões relativas à saúde ocupam posição central no cotidiano da sociedade, tornando-se foco de atenção de governos, empresas e comunidades (Paim, 2009), assim como dos meios de comunicação midiáticos. As crises sanitárias são pautadas pela imprensa, haja vista que, além de corresponder a um modo de se levar a vida, a saúde compõe um setor da economia no qual se produzem bens e serviços (Paim, 2009). 0 papel da mídia na comunicação sobre saúde é relevante, uma vez que ela pode auxiliar os governos na tomada de decisão sobre as ações que provocam implicações na vida das pessoas.

A comunicação, para além dos aspectos de prevenção e promoção, é importante para as relações entre os profissionais de saúde e a população, na busca por informação, na adesão às recomendações do setor e na educação do cidadão quanto ao acesso aos serviços de saúde (Pessoni, 2007). Este artigo busca refletir sobre como esse contexto influencia a cobertura da mídia brasileira sobre a vigilância sanitária, tema presente no cotidiano do cidadão comum, dada sua presença em diversos serviços, ações (hospitais, laboratórios, consultórios, clínicas, centros e postos de saúde) e bens (medicamentos, vacinas e equipamentos) de saúde (Paim, 2009). Essa relação entre a comunicação e a saúde tem o propósito de aumentar o conhecimento e a compreensão das questões relacionadas à saúde, proporcionando às pessoas informações para que desenvolvam suas vidas com qualidade (Schiavo, 2007). 0 primeiro periódico específico da área, o Journal of Health Communication, em 1986, definiu a comunicação em saúde como:

un campo de especialización de los estudios comunicacionales que incluye los procesos de agenda setting para los asuntos de salud; el involucramiento de los medios masivos con la salud; la comunicación científica entre profesionales de la biomedicina; la comunicación doctor/paciente; y, particularmente, el diseño y la evaluación de campañas de comunicación para la prevención de la salud. (Pintos, 2001)

Araújo e Cardoso (2007) já dissertaram sobre as relações entre a comunicação e a saúde, trazendo-as 
como campos de saber em diálogo com os princípios do Sistema Único de Saúde (SUS), ao pautar a importância da participação social e da descentralização, entre outros aspectos, como fundamental para a disseminação da voz dos profissionais de saúde, mas considerando também os saberes tradicionais, o comportamento individual, os determinantes sociais, econômicos e políticos, com a identificação de outras vozes para além das autorizadas.

No caso da imprensa brasileira, em particular, diferentes estudos já apontaram as potencialidades e os problemas da cobertura midiática sobre a saúde. Os equívocos vão desde a dificuldade em apresentar a complexidade do SUS, apresentando-o como algo predominantemente de cunho negativo (Silva; Rasera, 2013; Machado, 2014; Moraes; Oliveira-Costa; Mendonça, 2017), à soberania do saber especializado em detrimento das vozes dos indivíduos que são tema das reportagens (Oliveira-Costa et al., 2016).

O fato é que a imprensa comunica sobre saúde. Portanto, há a necessidade de essa produção ser constantemente analisada e avaliada, inclusive para pautar intervenções, seja na dinâmica de comunicação dos órgãos de saúde para com a imprensa, seja nas próprias redações de jornal. É sabido que o setor passa por redução de seus quadros de funcionários, o que prejudica uma apuração elaborada. Todavia, é importante que os pesquisadores estejam em constante vigilância sobre essa comunicação midiática sobre a saúde.

Tratando-se, especificamente, da Agência Nacional de Vigilância Sanitária (Anvisa), órgão do SUS que possui representações em todo o país, coordenando portos, aeroportos, fronteiras e alfândegas, já foi observado que quatro diferentes jornais brasileiros não dão espaço de fala qualificada aos indivíduos nas reportagens sobre vigilância sanitária, retratando-os como meros consumidores (Ferrari; Moura, 2009).

Busca-se, nesta pesquisa, observar como essas temáticas são relacionadas, nas narrativas midiáticas, ao próprio SUS. Para tanto, adota-se o termo narrativas midiáticas, por se considerar os textos jornalísticos como construções narrativas (Marques, 2016). Dessa forma, a pergunta de pesquisa que orientou esta investigação foi: como foi realizada a cobertura da imprensa brasileira dos temas pertinentes à vigilância sanitária em 2018?

Em sua Política de Comunicação (Brasil, 2014), a Anvisa afirma que "a credibilidade da Agência se constrói e se afirma pela forma como ela se relaciona com seus públicos e pela transparência de suas ações”. Porém, esse relacionamento passa pela imprensa como mediadora entre o trabalho desenvolvido na agência e a percepção dos brasileiros sobre esse trabalho. Portanto, cabe compreender como a imprensa brasileira apresentou, ao longo do ano, as ações da Anvisa aos brasileiros, a partir da análise de narrativas que a mencionam em seus textos.

\section{Métodos}

A pesquisa é descritiva e exploratória (Creswell, 2010), com amostra de textos jornalísticos coletados ao longo do ano de 2018 do arquivo de clipping disponibilizado em sítio eletrônico e utilizado pelo Ministério da Saúde à época, por semanas intercaladas - sete dias por mês, totalizando 84 dias de coleta em doze semanas completas.

Para a amostra, foram incluídos manualmente, por meio da ferramenta de busca, textos identificados que continham a palavra-chave Anvisa em veículos impressos e on-line, excluídos os institucionais, inclusive agências de notícias, a exemplo da Agência Brasil e Agência Câmara. Desde a década de 1980, análises de conteúdo investigam cientificamente a percepção das pessoas sobre saúde e doença e também como as mensagens sobre doença e tratamentos auxiliam a saúde pública. Os dados foram coletados em formulário de análise de conteúdo (Bardin, 2016), contendo as seguintes categorias: a data, o dia da semana, o tipo de mídia e a região do veículo, o gênero jornalístico, a área de atuação da Anvisa à qual o texto se refere, a frequência de assuntos em cada uma das áreas de atuação, as fontes dos textos e sua referência à Anvisa, bem como uma aferição da conotação (positiva, negativa ou neutra) do título em relação à imagem da Agência. Da mesma forma, dados relacionados à relação da Anvisa com o SUS, à presença de personagens, à responsabilização do órgão e à citação da vigilância local também foram coletados. Após a coleta de dados e a limpeza dos arquivos, foi utilizada a frequência de variáveis para 
apresentar o panorama de cobertura da vigilância sanitária na imprensa brasileira.

Realizou-se um teste do instrumento de pesquisa, utilizando cinco diferentes textos similares aos da amostra, com análise realizada pela equipe de pesquisadores de forma independente. Ao longo do processo de coleta de dados, foram realizadas reuniões periódicas para sanar dúvidas relacionadas às categorias. Ademais, ressalta-se que a pesquisa não foi submetida a nenhum comitê de ética, em razão de se tratar de dados secundários, provenientes de fonte de domínio público ou restrita aos assinantes dos jornais.

\section{Resultados e discussão}

Ao longo dos doze meses de 2018, foram coletados 1.629 textos. Entre os veículos digitais que mais publicaram matérias mencionando a Anvisa destacam-se: G1 - Globo (94), R7 (62), Terra Notícias (61), UOL Notícias (57), O Globo (48), Exame. (39), Folha (38), IstoÉ (34), IstoÉ Dinheiro (33) e Gazeta do Povo (32). Por outro lado, os jornais impressos que mais veicularam textos com referência à agência foram: Folha de S. Paulo (28) e A Tribuna (28), ocupando as $13^{\mathrm{a}}$ e $14^{\mathrm{a}}$ posições, respectivamente. Quanto ao tipo de mídia, 1.219 textos são de veículos digitais (75\%) e 410 de jornais impressos (25\%). Ao todo, 148 veículos distintos publicaram artigos relacionados à Anvisa (91 digitais e 57 impressos). No que se refere ao alcance, 738 textos foram publicados em meios de comunicação nacionais distintos (45,3\%) e 891 em regionais $(54,7 \%)$. Os veículos das regiões Nordeste (271) e Sudeste (26o) foram os que mais publicaram no período analisado, enquanto a região Centro-Oeste foi a que apresentou menos publicações (79). A predominância de veículos digitais e de publicações nesse meio é característica da era digital, com superabundância de informações e de canais, além do baixo custo de produção. Tal revolução tecnológica afetou o jornalismo e a comunicação de forma profunda, radical e abrangente, considerada a maior revolução nos meios de produção, registro, armazenamento, processamento e transmissão da informação, em toda a história (Kucinski, 2018).
Em relação aos gêneros jornalísticos, foram identificadas 607 notícias, 536 reportagens, 336 notas, 68 textos opinativos e 37 entrevistas. Cabe destacar que, como órgão federal de regulação e monitoramento em saúde, a Anvisa foi mencionada em 45 informes publicitários, os quais são formatados como notícia, todavia, não têm qualquer compromisso com os valores de noticiabilidade e credibilidade. Informar que algum novo produto ou serviço tem a chancela da Anvisa foi a estratégia de diferentes anunciantes, o que merece atenção da área de comunicação da autarquia, para verificar em que medida essas informações procedem sem trazer prejuízos à imagem do ente público.

A Anvisa foi notícia predominante para as ações relacionadas à regulamentação, ao registro e às autorizações (58,2\%), seguida de textos referentes à fiscalização e ao monitoramento (30,8\%). Há pouco espaço na imprensa para textos relacionados à articulação política e institucional (4,4\%), ao Sistema Nacional de Vigilância Sanitária (3,7\%) e à educação e à pesquisa $(2,4 \%)$ ou outros temas $(0,5 \%)$. O que é incluído na agenda dos meios de comunicação corresponde a um conjunto de valores-notícia, que auxiliam os profissionais de comunicação a avaliar o potencial de algo ganhar as páginas do jornal (Hohlfeldt, 2015). Considerando-se que a Anvisa é notoriamente mais conhecida para os temas de regulamentação e fiscalização, este resultado não surpreende. Cabe compreender, então, sob que perspectivas esses temas foram pautados.

A mídia, por meio dos valores-notícia, decide sobre o que o público deve pensar ou debater. Dentre os assuntos frequentes nas matérias da amostra analisada, destacam-se medicamentos e farmacopeia (27\%) como os assuntos com maior frequência, sendo referenciados em textos que exploram registros de novos produtos ou fiscalizações e apreensões. A Anvisa é mencionada como a que aprova ou proíbe os mais diversos remédios regulares, como antibióticos, insulina, melatonina, genéricos e manipulados, ou irregulares, como "boa noite, Cinderela", judicialização do canabidiol e terapias combinadas, assim como com nomes fantasia, como "pílula da inteligência" e "pílula do câncer". Essa alta frequência do tema de medicamentos pode explicar-se por causado valor-notícia de interesse público. 
Sequencialmente, destacam-se os textos relacionados aos produtos para a saúde (órteses, próteses, materiais hospitalares, luvas, implantes etc.), com percentual de $12 \%$. Neste grupo, foram publicadas matérias sobre lentes de contato, materiais cirúrgicos e sensores, sendo mais da metade relacionadas ao óbito, devido ao procedimento estético realizado por um médico blogueiro conhecido como Dr. Bumbum, com uso de substância autorizada pela Anvisa, o polimetilmetacrilato (PMMA), conforme mencionado no início da análise. Ademais, cabe destacar que, em razão da repercussão do caso do Dr. Bumbum, o mês de julho foi o que mais apresentou publicações sobre a agência na mídia, conforme demonstrado no Gráfico 1.

\section{Gráfico I - Distribuição da amostra ao longo de 2018}

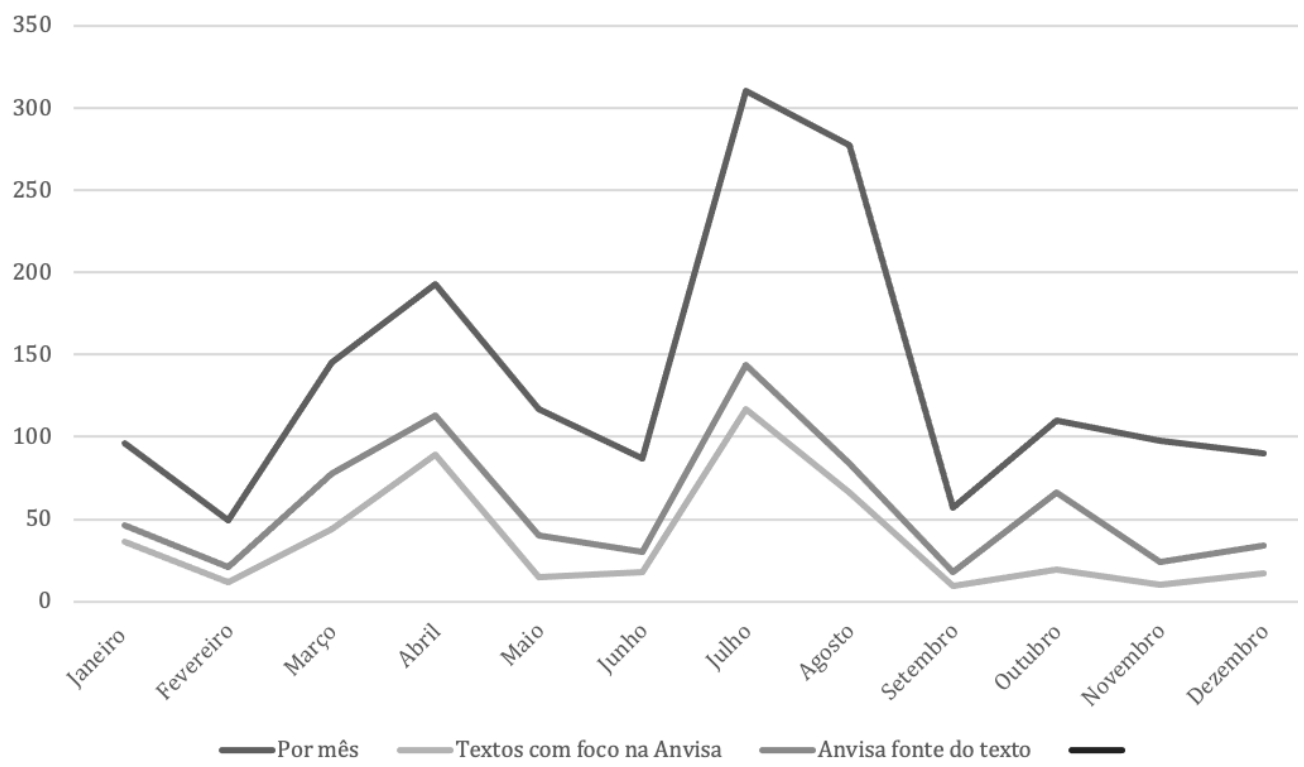

Dos 310 textos coletados nesse mês, 85 textos repercutiram o caso. Após as primeiras notícias sobre a morte da paciente, as publicações tinham como foco os procedimentos estéticos e as substâncias utilizadas, os detalhes da investigação e a prisão do médico. Do caso, derivaram novas publicações com alertas sobre o uso de substâncias, os procedimentos estéticos e os profissionais habilitados. Por meio da agenda setting, agendamento de assuntos julgados prioritários na discussão pública na imprensa, os meios de comunicação constroem a realidade a partir da seleção dos temas a serem repercutidos (Lopes, 2018). Conforme Monteiro (2018), são as notícias que determinam quais acontecimentos têm direito à existência pública e que, por isso, figuram na agenda de preocupações da opinião pública como temas importantes. A elas também é atribuída a definição dos significados desses acontecimentos, ao oferecer interpretações de como compreendêlos. Ainda, considerando o caso mencionado, é interessante notar um reposicionamento da vinculação da Anvisa ao fato. Os primeiros textos sobre a morte da paciente, publicados nos primeiros dias da cobertura jornalística, citam a autarquia como órgão regulador que autoriza a utilização do material, trazendo alguma legitimidade ao procedimento adotado pelo profissional de saúde responsável pelo atendimento. Porém, os textos subsequentes passaram a apresentar a informação de que a agência, apesar de autorizar o uso do referido produto, não o recomendava para o fim para o qual foi utilizado, ocasionando o óbito da paciente. Possivelmente, pode ter ocorrido alguma intervenção da assessoria de comunicação da Anvisa sobre os meios de comunicação para correção e ajustes nos textos.

O terceiro assunto mais frequente na amostra refere-se à área de alimentos (10\%). Os textos discorrem predominantemente sobre a regulamentação e a fiscalização dos mais variados 
produtos, com informações sobre carnes, trigo, soja, azeite, água, sobre os produtos de dietas específicas, como o sal rosa do Himalaia, alimentos integrais, veganos, sem glúten, lactose, carboidratos incluindo até as novidades no setor, como kombucha, semente da papoula e hambúrguer de casca de banana. Assim, a tematização promovida pela imprensa em relação à Anvisa pode estar relacionando a saúde como bem de consumo e à medicalização da vida. Conforme Lefévre (1999) aponta, se a mensagem na imprensa não traz um argumento para a coletividade, mas uma indicação individual sobre remédios e tratamentos para este ou aquele público, a imprensa apresenta uma saúde coletiva, porém, de prescrição individual.

Os demais temas tiveram frequência inferior a um décimo do total de textos, conforme o Gráfico 2.

\section{Gráfico 2 - Frequência de assuntos publicados nos textos sobre a Anvisa da amostra, jan./dez. 2018}

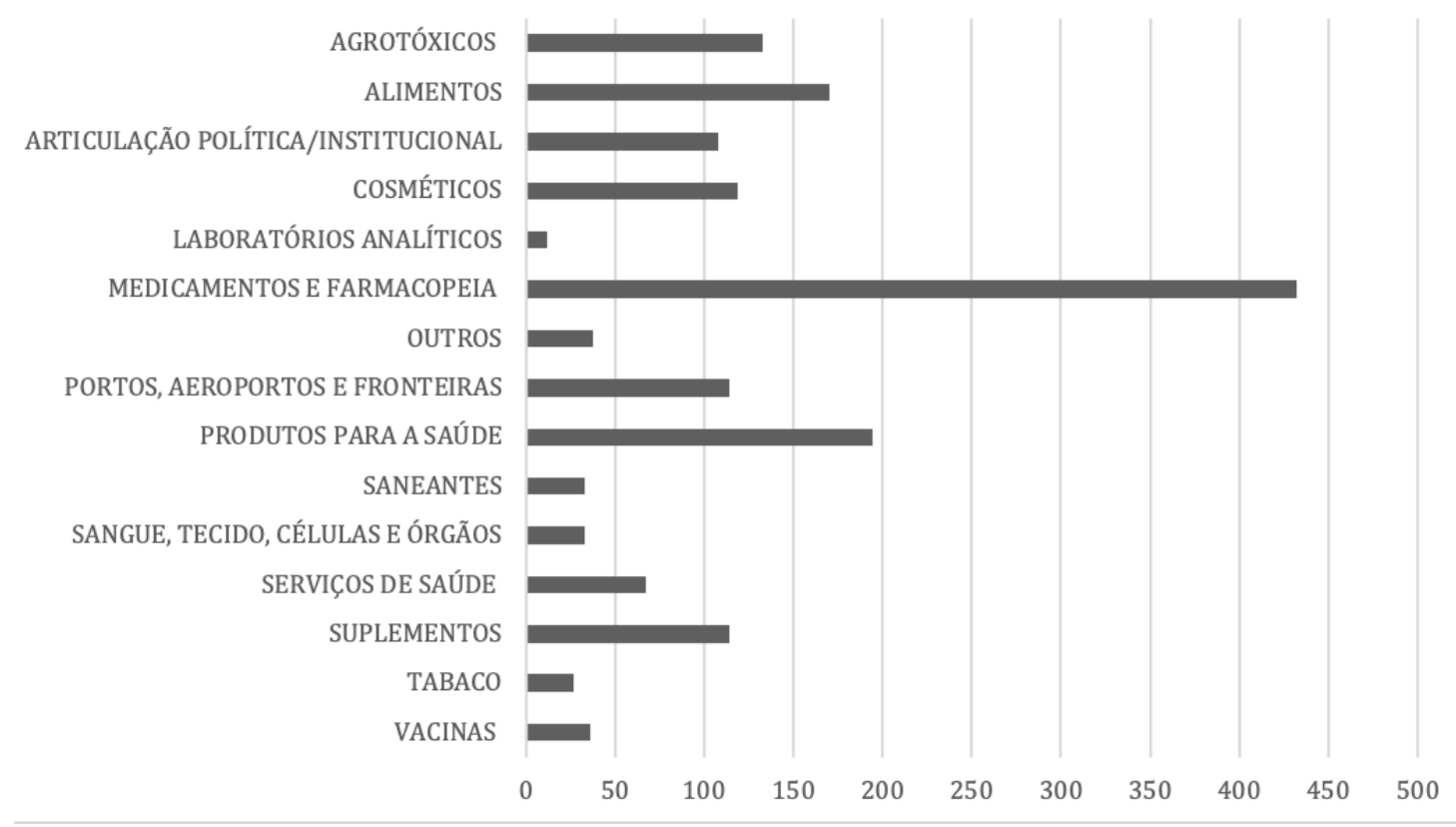

Os dados quanto à presença da Anvisa nos títulos dos textos apresentam pelo menos dois aspectos relevantes. 0 primeiro, e mais evidente, é que muito embora a coleta de dados tenha sido realizada a partir da recuperação da palavra Anvisa, ou seja, a amostra de 1.629 textos, o referido termo consta em apenas 351 títulos, representando 21,5\% do total analisado. Assim, a maior parte dos textos analisados não dá destaque ao nome da Agência nos títulos. O fato em si não chega a surpreender, uma vez que os critérios jornalísticos por meio dos quais os títulos das matérias são construídos fazem com que essas chamadas atraiam a atenção do leitor para aquilo que é mais enfático no texto. Os títulos funcionam, conforme apontam Serra e Santos (2003), “como uma propaganda, chamam a atenção, apresentam as questões que motivam a leitura e qualificam a informação". O fato de não estar presente na maior parte dos títulos de textos sobre vigilância sanitária evidencia certa ausência do órgão na cobertura midiática sobre o tema.

O segundo aspecto a despertar a atenção é que nem sempre a Anvisa é o foco da notícia, mesmo quando é mencionada no título do texto. Tal ocorrência foi verificada em 54 das 351 publicações que possuem a palavra Anvisa no título. Percebe-se, na verdade, que o nome da autarquia pode ter sido utilizado para referendar a informação prestada, sem, no entanto, dar maior espaço à Anvisa em relação a outros atores dos conteúdos analisados.

Sobre o qualificador dos títulos, nota-se que quase a totalidade dos textos (99,5\%) foi classificada como neutra, ou seja, sem a presença de expressões ou palavras que tragam 
adjetivações ou críticas relacionadas à Anvisa. Os títulos podem determinar como um leitor vai construir o sentido sobre o texto, antes de uma leitura completa e, neste caso, foi observada a construção de títulos com objetividade, sem que se percebesse a intencionalidade de cada texto apenas pelo título (Barros-Filho; Bertolozzi, 1995). Por fim, nota-se que os títulos que comportam a palavra Anvisa são majoritariamente de veículos de comunicação digitais, totalizando 306 , enquanto os de veículos impressos totalizaram 45. De igual forma, a mesma lógica foi verificada entre os 1.278 títulos que não mencionaram a Anvisa (913 digitais e 365 impressos).

Neste sentido, há o seguinte questionamento: será que a Anvisa foi o foco dos textos publicados? Não, para 72,2\% da amostra. Apenas 452 textos apresentam a Agência como núcleo das publicações. Ademais, embora citado, o órgão é a fonte de informações em menos da metade dos textos analisados: dos 1.629 textos, a agência teve voz em apenas 698 (42,9\%), em contrapartida aos 931 textos em que não aparece nessa condição, apesar de discutirem sobre vigilância sanitária. Correia (2011) entende fonte como “(...) todos os agentes sociais dispostos a colaborarem com os jornalistas no fornecimento de material informativo considerado de interesse pelos jornalistas". Sabe-se que o uso de fontes é um relevante recurso jornalístico, utilizado tanto para explicar um dado assunto quanto para agregar credibilidade à informação prestada, seja ela técnica ou política. Mont'Alverne e Marques (2015) ajudam a compreender melhor o papel da fonte quando atestam que:

Em diversos casos, a cobertura é construída a partir das declarações de agentes oficiais e de especialistas, priorizando suas perspectivas, já que eles estariam em posição de saber das informações, ocupando o posto de fontes confiáveis às quais os profissionais devem recorrer para validar suas matérias. (Mont'Alverne; Marques, 2015)

A fonte é utilizada pelos veículos de comunicação como uma instância capaz de assegurar a isenção da notícia veiculada, distanciando, assim, a opinião do jornalista que a redige do fato a ser reportado. Muitas vezes, mais do que o papel de prestar esclarecimentos sobre temas diversos, a fonte pode definir a credibilidade que o meio de comunicação tem como público. Ou, nas palavras de Strömbäck e Nord (2006), as fontes de informação, sendo pessoas de muito poder, podem ter a capacidade de "outorgar legitimidade às histórias".

AAnvisa éreconhecida pelos meios de comunicação como a agência nacional reguladora e de vigilância sanitária. Entretanto, é procurada pelos mesmos veículos em menos da metade das publicações $(42,9 \%)$ para repercutir conteúdos que tratam das normas, das regulações e dos temas e assuntos que abrangem sua atuação. Em um contexto no qual se observa uma disputa pela visibilidade midiática, e o que existe é o que está na mídia (Monteiro, 2018, p. 117), é necessário pensar em alternativas que garantam espaço aos posicionamentos da agência para além das menções, visto que:

É no espaço de mediação, mobilizado pelos diversos campos sociais para agirem politicamente em favor de seus interesses - e que hoje está ampliado para abrigar o ciberespaço - que circula o discurso da opinião pública. Sempre que um campo procura interferir no outro, o recurso à opinião pública confere-lhe a legitimidade representativa de sua pretensão. (Monteiro, 2018, p. 118)

Ainda que a Anvisa seja o órgão responsável pela regulação, pelo registro e pelas autorizações, parte da imprensa brasileira optou por não repercutir em parceria com o órgão responsável, os conteúdos mencionados, atribuindo a ele apenas a responsabilidade. Buarque afirma que:

Alucinada pela intermediação da mídia, a população vê um mundo diferente da realidade, ou apenas pequenas partes dela: as partes escolhidas de um mundo produzido pelas mãos dos jornalistas, sobre o teclado do computador ou o foco da câmera. Ao mesmo tempo em que oferece todas as vantagens da transparência, sem a qual não há democracia, a imprensa comete equívocos que manipulam a realidade, servindo para embaçar, no lugar de clarear a realidade. (Buarque, 2018, p. 14) 
Autores como Corrado, citado por Monteiro (2018, p. 123), defendem que a comunicação legítima e digna de crédito da instituição com seus públicos de interesse passa a ser uma necessidade comercial, dada a competição em um mercado carregado de questões públicas (fusões, privatizações, orçamento público, demandas das minorias, preocupações ecológicas, segurança pública etc.). Assim, as instituições têm de se envolver com a mídia para atingir os públicos cujas opiniões orientam as políticas nacionais e as ações políticas; a mídia passa a ser a arena ou o campo social no qual os interesses tornam-se visíveis na batalha pela conquista do apoio da opinião pública (Monteiro, 2018, p. 123).

Os textos analisados repercutem vozes de diversos sujeitos para além daqueles ligados à Anvisa. Bubnova (2011) nos apresenta a ideia de que a voz "se identifica com opinião, ideia, ponto de vista, postura ideológica”. Daí a relevância de se compreender a estratégia jornalística de atribuir poder de fala a determinados sujeitos. A pesquisa permitiu observar que a grande maioria deles são aqueles ligados a alguma instância de governo, com 697 registros. Em seguida, as vozes mais recorrentes são as dos profissionais de saúde, com 424 ocorrências, e as do setor privado, com 412. A população e os movimentos sociais aparecem com 346 registros, e a ciência, com 341. Por vezes, várias vozes aparecem em um mesmo texto. Neste caso, faz-se pertinente observar que os textos analisados buscaram referendar seus conteúdos com agentes ligados ao poder público.

Além disso, foi observado que $20,5 \%$ da amostra (334 textos) têm a presença de personagens. De acordo com Sodré e Ferrari (1986), a humanização do relato é uma das características da reportagem, a qual oferece mais detalhamento e contextualização do que uma notícia, e escolhe um personagem para ilustrar o tema que pretende desenvolver, como num conto, em que a dramatização de uma situação concentra a ação em torno de um personagem. 0 personagem pode aparecer na narrativa como autônomo, com vida própria, ou acidentalmente, para ilustrá-la. Ferrari e Moura (2009) já observaram, em análise de conteúdo de quatro jornais nacionais, que reportagens sobre vigilância sanitária não dão espaço para atores sociais, retratando os indivíduos como consumidores e não como cidadãos que contemplem aspectos de qualidade de vida e socioambientais. As autoras também referiram que a imprensa não valoriza a pessoa como interessada nos assuntos de saúde e ressalta mais os atores econômicos em detrimento da própria vigilância sanitária e das pessoas.

Menos de $3 \%$ do total da amostra (43 textos) citam ou fazem alguma referência ao SUS. Esta informação, importante para a comunicação da saúde pública brasileira, é praticamente invisibilizada em quase toda a amostra. Moraes, Oliveira-Costa e Mendonça (2017) perceberam que não é comum a utilização do termo 'Sistema Único de Saúde' ou da sigla 'SUS' nos textos jornalísticos que tratam sobre os serviços públicos de saúde. Segundo as autoras, os textos que citam a sigla tendem a desvalorizar a imagem do sistema, trazendo em seus títulos e manchetes palavras, expressões ou frases de sentido pejorativo. Há, portanto, o problema da divulgação incoerente da imagem negativa do SUS, fato já comprovado por pesquisas realizadas na Folha de São Paulo (Silva; Rasera, 2013) e em O Globo (Machado, 2014). Acredita-se que parte da imagem negativa que os brasileiros têm do SUS pode ter forte influência das informações às quais têm acesso por meio dos veículos de comunicação. Estes constroem sua agenda de pautas essencialmente baseadas nas situações negativas e nos problemas do sistema de saúde, com pouco ou nenhum espaço para as experiências positivas e exitosas. No período analisado, a Anvisa, como espaço regulador do sistema, é retratada pela imprensa quase que absolutamente sem qualquer menção ou vinculação ao SUS. A partir da análise de quinze anos de cobertura jornalística brasileira sobre temas interessantes para a saúde coletiva, observou-se que os jornais apresentam "uma suposta ineficiência do Estado, incompetência das autoridades ou dos profissionais da área, levando à construção de uma ordem simbólica pouco reflexiva sobre o campo da política de saúde representada pelo SUS" (Langbecker et al., 2019). Dado que o SUS praticamente não é mencionado em textos sobre a Anvisa, é como se a agência não integrasse o sistema, ou seja, o Estado não estaria participando da autarquia nem contribuindo com a sua atuação, e a interface comunicação-saúde conformaria-se em "redes de cooperação, conflito, visibilidades, invisibilidades 
e onde se situam social e simbolicamente sujeitos" (Pitta, 1995, p. 258).

Na mesma amostra, em quase metade dos textos (805), é preocupante a não-responsabilização da Anvisa nas questões de vigilância sanitária. Contudo, nos artigos em que aparece como responsável, há complicadores descontextualizados do teor dessa responsabilização, como no caso do Dr. Bumbum, em que os textos expressam que a substância utilizada pelo médico é autorizada pela agência, mas não explicam que não é recomendada para aquele fim utilizado pelo profissional de saúde em questão. Além disso, cabe observar que apenas 4,7\% da amostra citam as vigilâncias de saúde locais, o que se deve, provavelmente, à utilização do termo "Anvisa" como palavra-chave na coleta de dados, porventura uma das limitações da pesquisa. Além disso, é importante considerar que a coleta foi realizada a partir de um banco de dados específico cedido aos pesquisadores pelo Ministério da Saúde e baseado em palavras-chave.

\section{Considerações finais}

A pesquisa apresentou um panorama sobre a Anvisa na imprensa brasileira ao longo do ano de 2018. A partir da aleatoriedade na coleta de dados, foram observadas tendências que revelam como os meios de comunicação midiáticos têm apresentado a agência aos brasileiros, com enfoque maior para a regulamentação e os medicamentos, colocando-a distante do SUS e não a identificando como principal fonte quando se trata da vigilância em saúde. Em relação aos assuntos e temas mais apresentados pela imprensa, cabe ao gestor verificar se o retrato obtido com a pesquisa corresponde às prioridades da gestão para incidência na imprensa. Em caso negativo, sugerese a produção de pautas positivas em torno dos temas que obtiveram menor visibilidade no período analisado.

Ademais, vale ressaltar uma questão: por que a Anvisa não é considerada como fonte para os jornalistas, embora seja mencionada nos textos? Qualquer resposta mais assertiva a esta pergunta, neste momento, configuraria especulação, uma vez que a investigação em questão não se propôs a explicar tal fenômeno. Porém, assim como acontece em relação aos títulos, não seria estranho deduzir que o nome Anvisa carrega respeitabilidade técnica a ponto de ser citado como elemento legitimador das informações prestadas, em especial devido ao seu caráter normativo ou regulador de práticas e procedimentos sanitários diversos. Pode-se transpor a mesma lógica para a análise sobre o foco dos textos investigados. Neste sentido, recomenda-se maior aproximação da Anvisa com a imprensa e, em especial, com agências de notícias, a exemplo das mencionadas no estudo, para garantir sua voz nos textos cujo tema faça referência às suas áreas de atuação, visto que, a partir das repetições nos títulos coletados, é possível supor o uso de textos de agências de notícias e outros replicadores de conteúdo, e seu potencial de difusão e capilarização da informação. Entretanto, por não configurar objeto desta pesquisa, tal análise não foi aprofundada, apenas sinaliza questões relevantes para estudos futuros sobre esta possível relação.

Cabe destacar, ainda, que se faz necessário um esforço da Anvisa em se apresentar como órgão do Sistema Único de Saúde. Na amostra analisada, é perceptível que esta relação não é direta nem explicitada na maioria dos textos. Uma vez que uma das responsáveis pela comunicação sobre o Sistema Único de Saúde é a imprensa, é fundamental que órgãos como a Anvisa, que têm espaço midiático regular e produz pautas relacionadas diretamente ao cotidiano dos cidadãos, sejam reconhecidos por estes, por meio da imprensa, como um órgão que também integra o sistema público de saúde.

Os dados foram coletados em uma amostra de textos específica, não podendo ser generalizados a outros órgãos da administração pública nem a outros períodos de análise, mas sugerem tendências da cobertura nacional que podem orientar a tomada de decisão dos gestores da comunicação da Anvisa.

O estudo é importante para a área da comunicação em saúde e para a saúde coletiva e pode ser base para investigações comparativas com outros períodos de análise e amostras. A partir deste panorama, pode-se avançar também em investigações específicas sobre os veículos que mais publicaram textos sobre o órgão no período, bem como sobre outras mídias, como as redes sociais da autarquia, além de contribuir para a elaboração de análises que contemplem os discursos dos profissionais de comunicação da Anvisa. 


\section{Referências}

ARAÚJO, I. S.; CARDOSO, J. M. Comunicação e

Saúde. Rio de Janeiro: Fiocruz, 2007.

BARDIN, L. Análise de conteúdo. São Paulo:

Edições 70, 2016.

BARROS-FILHO, C.; BERTOLOZZI, P. L. Ética na comunicação: da informação ao receptor.

São Paulo: Moderna, 1995.

BRASIL. Agência Nacional de Vigilância Sanitária. Política de Comunicação da Anvisa:

Instituída em 14 de outubro de 2013 pela Portaria 1.649/Anvisa. Brasília, DF, 2014.

BUARQUE, C. Prefácio à $1^{\mathrm{a}}$ edição. In: DUARTE, J. Assessoria de Imprensa e relacionamento com a mídia: teoria e técnica. 5. ed. São Paulo: Atlas, 2018. p. 14-16.

BUBNOVA, T. Voz, sentido e diálogo em Bakhtin. Bakhtiniana, São Paulo, v. 6, n. 1, p. 268-8o, 2011. DOI: 10.1590/S2176-45732011000200016

CORREIA, J. B. O admirável mundo das notícias: teorias e métodos. Covilhã: Livros LabCom, 2011.

CRESWELL, J. Projeto de pesquisa: métodos qualitativo, quantitativo e misto. 3. ed. Porto Alegre: Artmed, 2010.

FERRARI, A. P.; MOURA, D. O. Consumo, cidadania e direito à saúde. A imprensa e o cidadão quando o assunto é o risco sanitário. Interin, Curitiba, v. 8, n. 2, 2009.

HOHLFELDT, A. Hipóteses contemporâneas da pesquisa em comunicação. In: HOHLFELDT, A.; MARTINO, L. C.; FRANÇA, V. V. Teorias da Comunicação: conceitos, escolas e tendências. 15. ed. Rio de Janeiro: Vozes, 2015. p. 187-240.

KUCINSKI, B. Prefácio à 5 a edição. In: DUARTE, J. Assessoria de Imprensa e relacionamento com a mídia: teoria e técnica. 5. ed. São Paulo:

Atlas, 2018.

LANGBECKER, A. et al. A cobertura jornalística sobre temas de interesse para a Saúde Coletiva brasileira: uma revisão de literatura. Interface Comunicação, Saúde, Educação, Botucatu, v. 23, e180oo95, 2019. DOI: 10.1590/Interface.180095
LEFÉVRE, F. A saúde como fato coletivo. Saúde e Sociedade, São Paulo, v. 8, n. 2, p. 83-91, 1999. DOI: 10.1590/So104-12901999000200005 LOPES, O. Glossário. In: DUARTE, J. Assessoria de Imprensa e relacionamento com a mídia: teoria e técnica. 5. ed. São Paulo: Atlas, 2018.

MACHADO, I. B. Percepções sobre o SUS: o que a mídia mostra e o relevado em pesquisa.

In: LENER, K.; SACRAMENTO, I. Saúde e jornalismo: interfaces contemporâneas. Rio de Janeiro, Fiocruz, 2014.

MARQUES, I. F. M. A construção da personagem nas narrativas do jornalismo digital. 2016. Tese. (Dissertação de Mestrado em Comunicação e Jornalismo) - Faculdade de Letras da Universidade de Coimbra, Coimbra, 2016.

MONT'ALVERNE, C.; MARQUES, F. P. J. A. A opinião da empresa no Jornalismo brasileiro: Um estudo sobre a função e a influência política dos editoriais. Estudos em Jornalismo e Mídia (UFSC), Florianópolis, n. 12, n. 1, p. 121-37, 2015. DOI: 10.5007/1984-6924.2015V12n1p121

MONTEIRO, G. A notícia institucional. In: DUARTE, J. Assessoria de Imprensa e relacionamento com a mídia: teoria e técnica. 5. ed. São Paulo: Atlas, 2018.

MORAES, R. C.; OLIVEIRA-COSTA, M. S. de; MENDONÇA, A. V. M. De que saúde pública estamos falando? Um olhar sobre os discursos jornalísticos no Correio Braziliense no ano de 2016. Revista Latinoamericana de Ciencias de la Comunicación, Butantã, v. 14, n. 27, 2017.

OLIVEIRA-COSTA, M. S. et al. Promoção da saúde da mulher brasileira e a alimentação saudável: vozes e discursos evidenciados pela Folha de SP. Ciência \& Saúde Coletiva, Rio de Janeiro, v. 21, n. 6, p. 1957-64, 2016. DOI: 10.1590/1413-81232015216.01702015

PAIM, J. S. O que é o SUS. Rio de Janeiro:

Fiocruz, 2009.

PESSONI, A. Comunicação para a saúde: estado da arte da produção norte-americana. Comunicação \& Inovação, São Paulo, v. 8, n. 14, p. 61-4, 2007. DOI: 10.13037/ci.vol8n14.675 
PINTOS, V. S. Comunicación y Salud.

Inmediaciones de lá Comunicación, Montevideo, p. 121-36, 2001. Disponível em: < https:// revistas.ort.edu.uy/inmediaciones-de-lacomunicacion/issue/view/224/27 >. Acesso em: 15 nov. 2014.

PITTA, A. M. R. Interrogando os campos da Saúde e da Comunicação: notas para o debate. In: PITTA, A. M. R. Saúde \& comunicação: visibilidades e silêncios. São Paulo: Hucitec, 1995. p. 258.

SCHIAVO, R. Health communication: from theory to practice. New York: Jossey-Bass, 2007.

SERRA, G. M. A.; SANTOS, E. M. Saúde e mídia na construção da obesidade e do corpo perfeito.
Ciência \& Saúde Coletiva, Rio de Janeiro, v. 8, n. 3, p. 691-701, 2003. DOI: 10.1590/S141381232003000300004

SILVA, G. M.; RASERA, E. F. A desqualificação do SUS na Folha de São Paulo: construção discursiva de gestores e usuários. Psico, Porto Alegre, v. 44, n. 1, p. 82-91, 2013.

SODRÉ, M.; FERRARI, M. H. Técnica de reportagem. São Paulo: Summus, 1986.

STRÖMBÄCK, J.; NORD, L. Do politicians lead the tango?: A study of the relationship between Swedish journalists and their political sources in the context of election campaigns. European Journal of Communication, London, v. 21, n. 2, p. 147-64, 2006.

\section{Agradecimentos}

Aos estudantes de graduação Italo Maximiliano Freitas, Carolina Magalhães de Souza Silva e à residente em Gestão de Políticas Públicas Rianna Moraes, pelo apoio à coleta de dados.

\section{Contribuição dos autores}

Cunha, Vasconcelos e Oliveira-Costa são responsáveis por todas as etapas do processo de coleta, interpretação dos dados e pela redação do artigo.

Recebido: 18/06/2020

Reapresentado: 28/07/2021; 13/09/2021

Aprovado: 21/09/2021 